American Journal of Infectious Diseases 3 (3): 159-164, 2007

ISSN 1553-6203

(C) 2007 Science Publications

\title{
Isolation and Identification of Listeria monocytogenes in Processed Meat by a Combined Cultural-molecular Method
}

\author{
${ }^{1}$ Angela Ingianni, ${ }^{1}$ Marta Quartuccio, ${ }^{1}$ Maria Antonietta Madeddu, ${ }^{2}$ Adriana Sanna, ${ }^{2}$ Sandro Dessì, and \\ ${ }^{1,3}$ Raffaello Pompei \\ ${ }^{1}$ Dipartimento di Scienze e Tecnologie Biomediche, Università di Cagliari, \\ via Porcell 4, 09124 Cagliari, Italy \\ ${ }^{2}$ Dipartimento di Sanità Pubblica, Università di Cagliari, via Porcell 4, 09124 Cagliari, Italy \\ ${ }^{3}$ Biotecne, via Nuoro 58, 09125 Cagliari, Italy
}

\begin{abstract}
The isolation and identification of Listeria monocytogenes in processed meat samples by a combined cultural-molecular method is described. It allows the identification of Listeria strains by means of a hybridization technique with a specific DNA probe directed to the listerial internalin gene. The specificity of this method was found to be $100 \%$ and sensitivity was as low as 1 CFU/2.5 g of food sample. A total of 278 meat samples were tested in comparison with PCR and conventional cultural assays. A total of $42(15.4 \%)$ L. monocytogenes were detected. PCR analysis gave 3 false negative results and culture failed to detect the Listeria in 5 cases. With this cultural-molecular method the identification and quantitative detection of L. monocytogenes were achieved within 36 hours and no false positive or negative tests were obtained, thus fitting most food industry requirements.
\end{abstract}

Key words: Listeria, DNA probe, food protection, membrane filtration

\section{INTRODUCTION}

Listeria monocytogenes is a Gram-positive intracellular bacterium, responsible for several severe infections in humans ${ }^{[1,2]}$. These diseases mainly affect newborn infants, immunosuppressed subjects, pregnant women and the elderly, but normal subjects can also suffer from listeriosis ${ }^{[3]}$. Uncooked or processed foods represent the most common cause of infection ${ }^{[4,5]}$, since Listeria monocytogenes is considered a post processing contaminant. Considering the increasing importance of this microorganism, many studies have recently been performed to set up new sensitive methods for detecting L. monocytogenes in foods in a short time, in order to meet the needs of the food industries ${ }^{[6,7]}$.

Conventional techniques, using cultural and biochemical assays, require at least 4-5 days for complete listeria identification; these methods are very specific and sensitive however the realization time is too long ${ }^{[8-10]}$.

Recently new molecular techniques have allowed more specific and rapid tests for detecting the presence of pathogens in foods ${ }^{[10-12]}$. The polymerase chain reaction (PCR) has been widely used for the amplification of various listeria virulence factors, namely invasion associated protein ${ }^{[8]}$, internalin $\mathrm{B}^{[13]}$, listeriolysin ${ }^{[8,14]}$. and aminopeptidase ${ }^{[15]}$. PCR was found to be specific, but not very sensitive, since preenrichment in selective media was generally necessary ${ }^{[16]}$; furthermore, some substances contained in the food samples could negatively influence the activity of the Taq DNA polymerase, with the possibility of obtaining false negative results ${ }^{[17,18]}$. Another important defect of this technique is its intrinsic failure in differentiating live from dead cells and in giving a quantitative record of the listeria contained in food samples ${ }^{[19]}$; in fact, a quantitative determination of the listeria content in a food sample is required for monitoring the real risk of infection caused by contaminated food ingestion ${ }^{[20,21]}$. The use of specific DNA probes ${ }^{[22,9]}$, reverse trascription PCR (RT-PCR) ${ }^{[23]}$. and nucleic acid sequence-based amplification (NASBA) ${ }^{[24]}$ were also used to overcome direct PCR defects. Real-time PCR is a rapid and specific method for determining food contamination by Listeria and other pathogens ${ }^{[25-27]}$, but it shows a modest sensitivity and does not allow the isolation of the detected pathogens, which can be useful for further biochemical and epidemiologic assays (Klein 2002; Rodrìguez-Làzaro et al. 2004) ${ }^{[28,29]}$. Moreover, RT-PCR and NASBA are influenced by a high mRNA concentration and need a pre-enrichment step to increase the assay sensitivity. Since several studies have shown that both DNA and mRNA may persist in a detectable form for many hours (up to 30) after death, these methods do not precisely assess the

Corresponding Author: $\quad$ Dr. Angela Ingianni, Dipartimento di Scienze e Tecnologie Biomediche, Sezione di Microbiologia Applicata, Via Porcell. nº4, 09124 Cagliari, Italy, Tel 070.6758487;Fax 070.6758482 
bacterial viability of pathogens in food (Keer and Birch, 2003). Listeria detection by specific DNA probes is another low-sensitive technique which needs preenrichment and thus takes at least 3-4 days for a complete analysis ${ }^{[4]}$. In a recent paper Carroll et al. ${ }^{[21]}$ described an interesting new technique which is able to make both a qualitative and quantitative analysis of $L$. monocytogenes in foods. It uses specific monoclonal antibodies and it is rapid and easy to perform, but it is not very specific and quite expensive.

In this paper, a combined cultural-molecular method, which employs nylon membrane filters for microbial concentration in food samples, is described. The study demonstrates that this method allows the detection and isolation of only living bacteria, is highly sensitive and specific and gives precise quantitative listeria detection within $36 \mathrm{~h}$.

\section{MATERIALS AND METHODS}

Bacterial strains and culture media: For assay development, 8 collection listeria strains were used. Four L. monocytogenes, 1 L. innocua, $1 \mathrm{~L}$. ivanovii, $1 \mathrm{~L}$. seeligeri and $1 \mathrm{~L}$. welshimeri are described in Table 1. Several other strains including Staphylococci, Enterococci, Gram-positive bacilli and E. coli were used as well.

Table 1: Strains of Listeria spp. and other bacteria used in this study

\begin{tabular}{ll}
\hline Species & Origin and strain \\
\hline Listeria innocua & NCTC 11288 \\
Listeria monocytogenes & NCTC 10527 \\
Listeria monocytogenes & NCTC 10357 \\
Listeria monocytogenes & NCTC 11994 \\
Listeria monocytogenes & ATCC 43249 \\
Listeria ivanovii & CIP 7842 Institut Pasteur \\
Listeria seeligeri & NCTC 11856 \\
Listeria welshimeri & NCTC 11857 \\
42 Listeria monocytogenes & Processed meat samples \\
20 Listeria spp. & Processed meat samples \\
20 non-Listerial strains & Collection strains \\
\hline${ }^{\mathrm{a}}$ Po
\end{tabular}

${ }^{\mathrm{a}}$ Pork sausages, beef meatballs, beef hamburgers.

Both non-selective and selective media were tested for performing the assay, namely Luria agar (LA, Difco, Italia), Oxford agar (Difco) and Aloa agar (Biolife, Italy). Listerial strains isolated from the various food samples were first identified by cultural, biochemical and metabolic methods and then also subjected to analysis using the API listeria galleries (Bio-Mèrieux, Italia). Identification was confirmed by a PCR technique.
Listerial membrane filtration and processing: A cell suspension $(10 \mathrm{ml})$ of each listerial sample containing about $5 \mathrm{CFU} / 1 \mathrm{ml}$ of peptone water was prepared. This suspension was filtered through a positively charged nylon membrane (Roche Diagnostics Corporation, Indianapolis, USA) with a diameter of $42 \mathrm{~mm}$ and a mesh of $0.45 \mu \mathrm{m}$. Then the membranes were picked up and put on a $45 \mathrm{~mm}$ Petri dish containing either selective or non-selective media. After an incubation times from 12 to $32 \mathrm{~h}$ at $37^{\circ} \mathrm{C}$, the colonies grown on the membranes were counted. The membranes were first treated with a denaturating solution $(0.5 \mathrm{~N} \mathrm{NaOH}$, $1.5 \mathrm{M} \mathrm{NaCl}$ ) for $15 \mathrm{~min}$ at room temperature and then with a neutralizing solution $(1.0 \mathrm{M}$ Tris- $\mathrm{HCl}, \mathrm{pH} 7.5$, $1.5 \mathrm{M} \mathrm{NaCl})$. After this, the membranes were washed with 2 X SSC buffer $(0.3 \mathrm{M} \mathrm{NaCl}, 30 \mathrm{mM} \mathrm{Na}$-citrate, $\mathrm{pH}$ 7.0) for $10 \mathrm{~min}$ at room temperature and the colony DNA was fixed with an UV lamp for $15 \mathrm{sec}$ (Hoefer UVC 500 Ultraviolet Crosslinker, Amersham Pharmacia Biotech).

DNA extraction, PCR assay and DNA-probe preparation: DNA extraction from 25 gr. food homogenate samples and PCR tests were performed as described in a previous article by Ingianni et al. ${ }^{[30]}$. Briefly, L. monocytogenes strain NCTC 10527 was used for DNA-probe preparation. The strain was incubated overnight in BHI (Brain Heart Infusion) at $37^{\circ} \mathrm{C}$; the DNA was extracted at $100^{\circ} \mathrm{C}$ for $10 \mathrm{~min}$, then the culture was centrifuged for $15 \mathrm{~min}$ at $2,000 \mathrm{~g}$ and the supernatant was stored at $-20^{\circ} \mathrm{C}$. The Digoxigenin (DIG)-labeled probe was prepared by the amplification of the listerial specific internalin gene with the previously described primers ${ }^{[31]}$, corresponding to the sequence published on the Gene Bank from 2041 to 2290 base pairs (accession No. M67471), using a PCR DIG-probe synthesis kit (Roche Molecular Biochemicals, USA). The assay was run for 30 cycles starting with a denaturating step at $94^{\circ} \mathrm{C}$ for $30 \mathrm{sec}$, annealing at $60^{\circ} \mathrm{C}$ for $30 \mathrm{sec}$ and an extension at $72^{\circ} \mathrm{C}$ for $1 \mathrm{~min}$. In each experimental step a positive control, containing the non-labeled nucleotides, and a negative control with a template-devoid standard mix was inserted. The PCR products were checked in an ethidium bromide stained $1.5 \%$ agarose electrophoretic apparatus for $60 \mathrm{~min}$ at $90 \mathrm{~V}$ and the gel was read in a UV transilluminator.

Listerial colony DNA hybridization and processing: The colony-bearing nylon membranes were put in glass-covered boxes and pre-hybridized with the DIGeasy Hyb solution (Roche Molecular Biochemicals, USA) for $1 \mathrm{~h}$ at $37^{\circ} \mathrm{C}$; the hybridization step was run 
for $2 \mathrm{~h}$ at $37^{\circ} \mathrm{C}$ with the DIG-easy Hyb which contained $40 \mathrm{ng}$ of a DIG-labeled denatured DNA probe. A colorimetric detection was then performed (DIG-DNA detection kit, Roche Molecular Detection kit); briefly, after two washes with $2 \mathrm{X}$ SSC-0.1\% SDS for $5 \mathrm{~min}$ at room temperature and 2 subsequent washes with $0.5 \mathrm{X}$ $\mathrm{SSC}-0.1 \% \mathrm{SDS}$ for $15 \mathrm{~min}$ at $68^{\circ} \mathrm{C}$, the membranes were washed and mildly shaken with the washing solution for $1 \mathrm{~min}$ (washing buffer: $100 \mathrm{mM}$ maleic acid, $150 \mathrm{mM} \mathrm{NaCl}, \mathrm{pH} 7.5 ; 0.3 \% \mathrm{v} / \mathrm{v}$ Tween 20) and with a blocking solution for $30 \mathrm{~min}$. The membranes were put in a solution of anti-DIG alkaline phosphataselabeled polyclonal antibodies $(150 \mathrm{mU} / \mathrm{ml}$ for $30 \mathrm{~min})$ and with a nitro-blue-tetrazolium and bromo-chloroindolyl-phosphate solution (NBT/BCIP). A dark-brown precipitate appeared around each colony where the double stranded DNA was bound to the specific antibody. The shortest time for obtaining listerial colonies capable of producing a colour precipitate as described above, was calculated using different incubation times from 12 to $32 \mathrm{~h}$. For the assay the membranes were first used for filtering $10 \mathrm{ml}$ of control samples, containing about $50 \mathrm{CFU}$ of $L$. monocytogenes and were then put on Aloa agar plates for variable times from 12 to $36 \mathrm{~h}$ at $37^{\circ} \mathrm{C}$. Subsequently, the same system was used for filtering and processing different amounts of various food sample homogenates.

Assay sensitivity detection: Various amounts (from 100 to $0.01 \mathrm{ng}$ ) of L. monocytogenes NCTC 10527 genomic DNA were spotted on nylon membranes and fixed with an UV lamp; the membranes were then hybridized with the DIG-labeled DNA probe, as described above, and checked for dark-brown colour development.

Food samples processing and testing: Different types of foods, which were found to be free of any listeria strains, were first inoculated with known amounts of the Listeria collection. An amount of $25 \mathrm{~g}$ of a food sample was diluted in $90 \mathrm{ml}$ of peptonized water and homogenized for $30 \mathrm{sec}$ in a Stomacher (PBI International, Milano, Italy) at $242 \mathrm{rpm} / \mathrm{min}$ and 484 round changes $/ \mathrm{min}$. The solid particles were left to sediment for about $15 \mathrm{~min}$ and $10 \mathrm{ml}$ of the lipid-free fluid supernatant were picked up and filtered through the nylon membranes as described by Carroll et al. (2000); each experiment was done in triplicate. The membranes were picked up and put on Aloa agar plates and incubated at $37^{\circ} \mathrm{C}$ for $12-32 \mathrm{~h}$. The light-blue colonies, which corresponded to the listeria colonies, were detected, counted and picked up for biochemical identification, before proceeding to bacterial DNA fixation, hybridization and detection, as mentioned above. Finally, the same procedure was applied to several commercial processed food samples (278 meat samples, including pork sausages, beef meat-balls and hamburgers) for assessing the reliability, specificity and sensitivity of the membrane-hybridization test. All these samples were also tested with PCR after enrichment and with the conventional culture method.

\section{RESULTS AND DISCUSSION}

\begin{abstract}
Listeria membrane filtration and colony hybridization: When listeria suspensions were membrane filtered, grown on Aloa agar and DNAhybridized, all the species produced light-blue colonies, but only the species L. monocytogenes was able to develop dark-brown precipitates in correspondence to the colonies grown on the nylon membranes (Fig.1).
\end{abstract}

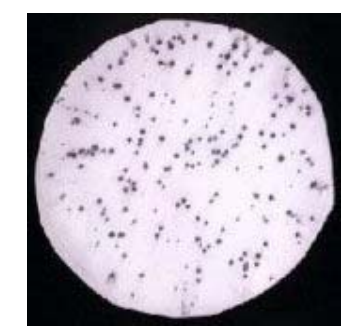

Fig. 1: DNA membrane-hybridization of Listeria monocytogenes; the figure shows numerous colonies of L. monocytogenes grown on nylon membrane filters in Aloa agar after the internalinprobe hybridization and colour development.

None of the other species of listeria tested were able to produce dark-brown colonies. Each stained spot was easily detectable on the membrane and, since each spot corresponded to one listeria colony, a precise quantitative determination of live listeria in the food sample was possible. All the L. monocytogenes tested were recognized, with no interference from other listeria species or other microorganisms tested. In fact, the assay employs a specific probe directed against the listeria internalin gene. This gene is only possessed by L. monocytogenes and is well conserved in all the pathogenic strains of this species ${ }^{[8]}$ whilst all the other listeria species lack it. Among the various media tested, the Aloa agar was the most effective in supporting the growth of Listeria spp. and in differentiating $L$. monocytogenes from other species of listeria in the membrane-hybridization assay. The LA medium provided good support for the growth of all species of bacteria, resulting in a reduced differentiating power, whilst the Oxford medium appeared as a very good selective and differentiating medium, but the presence of esculin, interfered with the typical dark-brown spots produced only by L. monocytogenes (data not shown). Thus, in all the subsequent experiments the Aloa medium was always used. 
The results obtained with different incubation times for the nylon membranes on selective media indicate that $20 \mathrm{~h}$ of incubation allowed the best growth of the listeria strains which formed easily detectable light-blue macroscopic colonies on the surface of the nylon membranes. Twelve $h$ were insufficient for obtaining macroscopic spots whilst $32 \mathrm{~h}$ did not give any visible advantage.

Detection of the assay sensitivity and specificity: The sensitivity of the membrane-hybridization method was assessed with different doses of DIG-labeled DNA probe and various amounts of listeria DNA. Marked and specific spots were detectable with doses of 40 $\mathrm{ng} / \mathrm{ml}$ of the internalin probe, which were able to detect as low as $0.1 \mathrm{ng}$ of listerial DNA (Fig.2A). This amount of DNA corresponds to a number of bacterial cells of about $3-5 \times 10^{7}$, which is the amount of bacteria found in a colony grown on agar plates for about $15-20 \mathrm{~h}$ in the conditions described in this work.

Various dilutions of the food samples were assayed. No interference on spotted colony development was observed with any sample or with any dilution of the samples. Only $L$. monocytogenescontaining specimens produced visible dark-brown specific spots.

A total of 278 food samples were tested with the membrane-hybridization method using various sample dilutions. As shown in Fig. 2B, it proved possible to detect and identify a single $L$. monocytogenes colony among other listerial species in a $10 \mathrm{ml}$ food homogenate-filtered membrane, which corresponded to $1 \mathrm{CFU} / 2.5 \mathrm{~g}$ of food. These findings indicate that this method has at least the same specificity as the culture method and a superior sensitivity and specificity to PCR amplification.

A

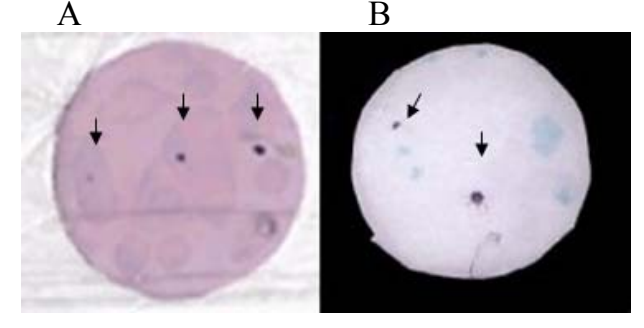

Fig. 2: Sensitivity of the nylon membrane-filtration method for identifying and counting of L. monocytogenes in homogenized food samples. In Fig.1A, three different spots representing different amounts of purified listeria DNA, are shown; from left to right $0.1,1.0$, and $10 \mathrm{ng}$ of DNA are indicated. In Fig.1B, two dark spots corresponding to two colonies of $L$. monocytogenes among several Listeria spp. colonies, grown on a membrane where $10 \mathrm{ml}$ of food homogenate were filtered, are detected.
The membrane-hybridization technique was compared to traditional culture methods and to PCR amplification (after enrichment) for L. monocytogenes detection in processed food samples (Table 2). A total of 278 different meat samples were assayed with these 3 methods. A total of 42 samples (15.4\%) resulted positive for $L$. monocytogenes by the membranehybridization assay; 3 of these samples were positive with both the cultural and the membrane-hybridization methods, but not with the PCR. In addition, 5 samples which were positive with PCR and membranehybridization, failed to give a positive reaction in the culture.

Table 2: Comparative analysis of the sensitivity of 3 different methods for detecting Listeria monocytogenes from processed meat

Detection of Listeria monocytogenes

\begin{tabular}{cccc}
$\begin{array}{c}\text { No. of meat } \\
\text { samples }\end{array}$ & Culture & $\begin{array}{c}\text { PCR } \\
\text { amplification }^{\text {a }}\end{array}$ & $\begin{array}{c}\text { Membrane } \\
\text { Hybridization }\end{array}$ \\
\hline 34 & positive & positive & positive \\
3 & positive & negative & positive \\
5 & negative & positive & positive \\
236 & negative & negative & negative
\end{tabular}

${ }^{a}$ After pre-enrichment

The membrane-hybridization assay appeared more effective and sensitive than conventional culture methods in the detection of L. monocytogenes colonies. In addition, it resulted as being much more rapid than the culture (results were obtained within 36 working h, compared to at least 3-4 days for cultures) and more sensitive than PCR. Furthermore, the membranehybridization technique was able to give a quantitative determination of live L. monocytogenes present in food samples, whereas simple PCR amplification did not allow this possibility. No false-positive or negative results were obtained, whereas both PCR and the culture method were found to sometimes produce falsenegative tests, probably due to a low number of Listeria present in some samples and to the presence of interfering substances in the food material. However, as it hapens for most standard Listeria isolation procedures, viable but not culturable strains (VBNC) are not detected by this system.

No method is actually considered superior to all others. This fact leaves plenty of room for the proposal of new or more sensitive tests which can overcome some of the problems presented by many of the assay 
systems described to date. Furthermore, the various USA Public Food Administration Authorities and also the European Administration Authorities ${ }^{[7]}$ tend to use different methods of analysis, which can not easily be compared. To the best of our knowledge, up till now a specific probe for the internalin gene has not been used on a membrane-filtration method on Aloa agar in a membrane-hybridization assay. The advantage of this combination (membrane filtration-Aloa agar-internalin) is the possibility of identifying only pathogenic $L$. monocytogenes and of giving a rapid and precise quantitative detection of Listeria in various food samples within $36 \mathrm{~h}$ with $100 \%$ specificity. This result can be very useful to food microbiologists and analysts and also to the food processing industry.

\section{ACKNOWLEDGEMENTS}

We acknowledge the collaboration of Biotecne in the organization and development of this project. The research grant was partially from the PRIN of the MIUR-Rome and from the Assessorato alla Sanità della Regione Sardegna.

\section{REFERENCES}

1. Farber, J.M. and P.I. Peterkin, 1991. Listeria monocytogenes, a food-borne pathogen. Microbiol. Rev. 55: 476-511

2. Vasquez-Boland, J.A., M. Kuhn and P. Berche et al., 2001. Listeria pathogenesis and molecular virulence determinants. Clin. Microbiol. Rev., 14: 584-640

3. Gray, M.L. and A.H. Killinger, 1966. Listeria monocytogenes and listeric infection. Bacteriol. Rev. 30: 309-382

4. Meng, J., and M.P Doyle, 1997. Emerging issues in microbiological food safety. Annu.Rev. Nutr. 17: 255-275

5. Kathariou, S., 2002. Listeria monocytogenes virulence and pathogenicity, a food safety perspective. J. Food Prot. 65: 1811-1829

6. Swaminathan, B., and P. Feng, 1994. Rapid detection of food-borne pathogenic bacteria. Annu. Rev. Microbiol. 48: 401-425

7. Entis, P. and I. Lerner, 2000. Twenty-four-hour direct presumptive enumeration of Listeria monocytogenes in food and environmental samples using the ISO-GRID method with LM-137 agar. J.Food Prot. 63: 354-363

8. Sado, P.N., K.C. Jinneman and G.J. Husby et al., 1998. Identification of Listeria monocytogenes from unpasteurized apple juice using rapid tests kits. J. Food Prot. 61: 1199-1202
9. Ingianni, A., M.A. Madeddu and G Lampis et al., 2000. Cultural and molecular methods for the identification of Listeria monocytogenes in environmental samples and foods. Res. Adv. Microbiol. 1: 61-68

10. Gasanov, U., D. Hughes and P.M. Hansbro, 2005. Methods for the isolation and identification of Listeria spp. and Listeria monocytogenes: a review. FEMS Microbiol. Rev. 29: 851-875

11. Schaferkordt, S., E. Domann and T. Chakraborty, 1998. Molecular approaches for the study of Listeria. In A. Brendan \& N. Dorrell (Eds.), Methods in Microbiology, vol. 27. Academic Press, N.Y. pp. 421-431

12. Rijpens, N.P. and L.M. Herman, 2002. Molecular methods for identification and detection of bacterial food pathogens. J. AOAC Int. 85: 984995

13. Pangallo, D., E. Kaclikova and T. Kuchta, et al., 2001. Detection of Listeria monocytogenes by polymerase chain reaction oriented to inlB gene. New Microbiol. 24: 333-339

14. Burtscher, C., P.A. Fall and P.A. Wilderer et al., 1999. Detection of Salmonella spp. and Listeria monocytogenes in suspended organic waste by nucleic acid extraction and PCR. Appl. Environ. Microbiol., 65: 2235-2237

15. Winters, D.K., T.P. Maloney and M.G. Johnson, 1999. Rapid detection of by PCR assay specific for an aminopeptidase. Mol Cell Probes, 13: 127-131

16. Fitter, S., M. Heuzenroeder and C.J. Thomas, 1992. A combined PCR and selective enrichment method for rapid detection of Listeria monocytogenes. J. Appl. Bacteriol. 73: 53-59

17. O'Connor, L., J. Joy and M. Kane et al., 2000. Rapid polymerase chain reaction/DNA probe membrane-based assay for the detection of Listeria and Listeria monocytogenes in food. J. Food Prot. 337-342

18. Norton, D.M., 2002. Polmerase chain reactionbased methods for detection of Listeria monocytogenes: toward real-time screening for food and environmental samples. J: AOAC Int. 85: 505-515

19. Keer, J.T. and L. Birch, 2003. Molecular methods for the assessment of bacterial viability. J. Microbiol. Methods 53: 175-183

20. Datta, A.R., M.A. Moore and B.A. Wentz et al., 1993. Identification and enumeration of Listeria monocytogenes by nonradioactive DNA probe colony hybridization. Appl.Environ.Microbiol. 59: 144-149 
21. Carroll, S.A., L.E. Carr and E.T. Mallinson et al., 2000. A colony lift immunoassay for the specific identification and quantification of Listeria monocytogenes. J. Microbiol. Methods 41: 145-153

22. Peterkin, P.I., E.S. Idziak and A. Sharpe, 1991. Detection of Listeria monocytogenes by direct colony hybridization of hydrophobic gridmembrane filters using a chromogen-labeled DNA probe. Appl. Envir. Microbiolol. 57: 586-91

23. Klein, D., 2002. Quantification using real-time PCR technology: applications and limitations. Trends Mol. Med. 8: 257-260

24. Cook N., 2003. The use of NASBA for the detection of microbial pathogens in foods and environmental samples. J. Microbiol. Methods 53: 165-174

25. Hein, I., D Klein and A. Lehner et al., 2001. Detection and quantitation of the iap gene of Listeria monocytogenes and Listeria innocua by a new real-time quantitative PCR assay. Res.Microbiol. 152: 37-46

26. Hough, A.J., S.A Harbison and M.G. Savill et al., 2002. Rapid enumeration of Listeria monocytogenes in artificially contaminated cabbage using real-time polymerase chain reaction. J. Food Prot. 65: 1329-1332
27. Koo, K. and L.A. Jaykus, 2003. Detection of Listeria monocytogenes from a model food by fluorescence resonance energy transfer-based PCR with an asymetric fluorogenic probe set. Appl. Environ. Microbiol. 69: 1082-1088

28. Klein, P.G. and V.K. Juneja, 1997. Sensitive detection of viable Listeria monocytogenes by reverse transcription-PCR. Appl. Environ. Microbiol. 63: 4441-4448

29. Rodrìguez-Làzaro, D., M. Hernàndez and M. Scortti, et al., 2004. Quantitative detection of Listeria monocytogenes and Listeria innocua by real-time PCR: assessment of hly, iap, and lin02483 targets and AmpiFluor technology. Appl. Environ. Microbiol. 70: 1366-1377

30. Ingianni, A., M. Floris and P Palomba et al., 2001. Rapid detection of Listeria monocytogenes in foods, by a combination of PCR and DNA probe. Mol. Cell. Probes 15: 275-280

31. Magi, G., B. Facinelli and P.E Varaldo, 1997. Sviluppo di una metodica basata sulla Polymerase Chain Reaction (PCR) per l'identificazione di Listeria monocytogenes e la possibile identificazione rapida della sua presenza negli alimenti. Microbiologia Medica 3: 215-217. 